\title{
An Analog of PKC412 Blocks Human Leukemia HEL Cells Growth Through STAT3/Mir-17-92/BIM Signal Pathway
}

\author{
Qing Rao ${ }^{1}$, Liping Wang ${ }^{1}$, Weiming Zhu ${ }^{1,2}$, Juan Chen ${ }^{1}$, Jingrui Song ${ }^{1}$ and Yanmei Li ${ }^{1 * *}$ \\ ${ }^{1}$ The key laboratory of Chemistry for Natural Products of Guizhou Province and Chinese Academy of Sciences,China \\ ${ }^{2}$ School of Medicine and Pharmacy, China
}

*Corresponding author: Yanmei Li, The key laboratory of Chemistry for Natural Products of Guizhou Province and Chinese Academy of Sciences, Guiyang, Guizhou, China

\section{ARTICLE INFO}

Received: 蔧 April 04, 2019

Published: 幽 April 15, 2019

Citation: Qing R, Liping W, Weiming Z, Juan C, Yanmei L. An Analog of PKC412 Blocks Human Leukemia HEL Cells Growth Through STAT3/ Mir-17-92/BIM Signal Pathway.

Biomed J Sci \& Tech Res 17(1)-2019. BJSTR. MS.ID.002945.

Keywords: miR-17-92; Apoptosis; Cell Cycle; Western Blot; qRT-PCR; Leukemia
ABSTRACT

Leukemia is a highly heterogeneous cancer and hematologic malignancy with a poor survival rate in patients. Developing novel anti-leukemia drugs with better selectivity and lower toxicity is required for the treatment of patients. Here we demonstrated that compound GZWM-060, an analog of midostaurin (PKC412), could exert higher effective against HEL cells growth than PKC412. The compound had a strong ability to block HEL cells growth through arresting cell cycle at G2 phase, inducing apoptosis. Interestingly, the compound could induce HEL cells differentiation into erythrocytes. The study of the mechanism showed that the compound could increase pro-apoptotic protein BIM level and inhibit of p-STAT3 and the six individuals of the cluster miR-17-92 (miR17, miR18a, miR19a, miR19b, miR20a, miR92). Therefore, these results indicated that the compound might be a lead molecule for the development of new anti-leukemia drugs candidates by targeting p-STAT3/miR-17- 92/BIM signal pathway.

\section{Introduction}

In the past few decades, cancer ranks as the most severe disease through uncontrolled cell growth, and it is a leading factor in death worldwide [1]. It is predicted that cancer deaths worldwide will reach more than 11.4 million [2,3]. So, the quantity demanded of anti-cancer drugs is sharp increasing all over the world. Sales of anti-cancer drugs have reached 36.4 billion US dollars and ranking the first among all kinds of medicines since 2010 [4]. Therefore, the prevalence of cancer and their resistance to the existing therapeutic agents necessitate the development of new medication that may overcome the limitation of existing drugs [5]. Leukemogenesis is induced through the emergence of neoplastic progenitors during hematopoiesis that subsequently undergoes clonal expansion leading to full- blown leukemia [6]. Leukemia contains four central subgroups: Chronic Myeloid Leukemia (CML), Acute Lymphoblastic Leukemia (ALL), and Chronic Lymphocytic Leukemia (CLL), Acute Myeloid Leukemia (AML) [7]. Midostaurin is the only FLT3 inhibitor approved by the FDA for the treatment of newly diagnosed FLT3-mutation AML in combination with systemic

chemotherapy [8] and demonstrated antiproliferative activity in a range of solid tumor lines, including lung, colon, breast, melanoma, and glioblastoma [9]. Drug resistance has been the limiting factors in the success of available treatments for cancers, development of resistance to PKC412A has been described recently [10-12]. Here we synthesized an analog of midostaurin (PKC412), GZWM-060. Employing the cytotoxicity assay, we discovered that GZWM- 060 had potent activity against leukemia cells, with minimal IC50 value. Therefore, we determine the mechanism of anti-cancer activity furtherly and found that the compound could exert higher effective against HEL cells growth than PKC412.

\section{Material and Method}

\section{Reagents}

Fetal bovine serum (FBS) was bought from the company HyClone (United State). Dimethyl sulfoxide (DMSO) was obtained from Sangon Biotech (Shanghai, China). Roswell Park Memorial Institute 1640 (RPMI-1640) and [3-(4, 5-dimethylthiazol- 2-yl)- 
2, 5-diphenyltetrazolium bromide] (MTT) were purchased from Sigma (Beijing, China). Annexin V-FITC Apoptosis Detection Kit was purchased from BD. TaKaRa, HiFiScript cDNA Synthesis Kit and UltraSYBR Mixture were purchased from TaKaRa (Beijing, China). Primers were prepared by Invitrogen (Shanghai, China). Other reagents were of analytical grade or guaranteed reagentcommercial product and used without further purification unless otherwise noted

\section{Cell Culture}

The human erythroleukemia cell line HEL was held by our laboratory. The cells were cultured in RPMI 1640 medium supplemented with $5 \% \mathrm{FBS}$ at $37^{\circ} \mathrm{C}$ in a $\mathrm{CO} 2$ incubator $(5 \% \mathrm{CO} 2$ and $95 \%$ air, 95\% humidity). The cells were passaged twice weekly to maintain an exponential growth phase.

\section{MTT Assay}

The cytotoxicity assay was accomplished by MTT assay. The assay is based on the alteration or conversion of MTT dye into red formazan derivatives. Cell plated at the density of 8000 cells per well in a 96 well-plate and treated with GZWM-060 at different concentrations ( 0.15 to $1 \mu \mathrm{mol} / \mathrm{L})$. In cell cytotoxicity assays, control groups were treated with either 1\% DMSO without GZWM-060. After 72 hours of treatment, per well were added MTT solution $20 \mu \mathrm{l}$ $(5 \mathrm{mg} / \mathrm{mL})$ for 4 hours respectively. 96 well - plate were centrifuged in $2500 \mathrm{rpm}$ with $15 \mathrm{~min}$, and discard the medium, then DMSO (150 $\mu \mathrm{l})$ was used to dissolve formazan crystals. The resulting solution was determined using absorbance at $490 \mathrm{~nm}$ (Thermo Scientific, Vario Skan Flash, USA). The growth curve of MTT was performed in 24, 48 and $72 \mathrm{~h}$. All experiments were carried out in triplicate and three independent tests. The percentage of cytotoxic activity compared to that of an untreated cell was determined as follows:

Cell viability $(\%)=($ OD sample - OD blank $) /($ OD control - OD blank $) \times 100 \%$

\section{Apoptosis Assay}

Cell were seeded at $1 \times 105$ cells per $60 \mathrm{~mm}$ dish in $3 \mathrm{~mL}$ medium with different concentration of GZWM-060 0.15 to 1 $\mu \mathrm{mol} / \mathrm{L}$ ), after grown $24,48,72 \mathrm{~h}$, the cell were harvested, washed 3 times with ice-cold PBS and transferred into microcentrifuge tubes for centrifugation at $220 \mathrm{~g}$ for $5 \mathrm{~min}$ at room temperature, then re-suspended in Annexin-binding buffer and $5 \mu \mathrm{L}$ of FITC and PI (BD FITC Annexin V Apoptosis Detection Kit I) were added to per Eppendorf tube, cells were vortexed, incubated for $15 \mathrm{~min}$ at room temperature in dark. Cells were analyzed by flow cytometry on an ACEA Novo cyte 1000 (ACEA Biosciences Inc., San Diego, CA, USA), PI binds to DNA when the cell membrane is disrupted and AV binds to translocated phosphatidylserine on the outer surface of the cell membrane (early apoptosis signal). Percentage of early apoptotic and late apoptotic/necrotic cell populations were calculated using Nove Express software (version 1.2.1, ACEA Biosciences Inc., San Diego, CA, USA) and compared with appropriate controls.

\section{Differentiation Marker Analysis}

The expression of CD235a (an erythrocyte differentiation marker) antigen on the surface of HEL cells were measured by flow cytometry. Cells were plated in $60 \mathrm{~mm}$ dish in $3 \mathrm{~mL}$ medium at $1 \times 10^{5}$ cells and exposed to different concentration of GZWM- 060 ( 0.15 to $1 \mu \mathrm{mol} / \mathrm{L}$ ) for $24 \mathrm{~h}$. After treatment, cells were washed with PBS twice, then incubated with CD235a (CD235a-APC) for one $h$ in the dark at $4^{\circ} \mathrm{C}$. The cells were washed twice with PBS and finally resuspended in $200 \mu \mathrm{L}$ PBS for measurement. CD235a expression levels were measured using flow cytometry (ACEA Biosciences Inc., San Diego, CA, USA).

\section{Cell Cycle Measurement}

HEL cells were seeded in 6-well culture plates at a density of $1 \times 105$ cells in $2 \mathrm{~mL}$ medium and were treated with GZWM-060 for different concentration ( 0.15 to $1 \mu \mathrm{mol} / \mathrm{L}$ ) for 18 and $24 \mathrm{~h}$. After the incubation, the cells were collected and transferred into a sterile centrifuge tube for cell cycle analysis. Cells were washed with precool PBS and suspended in 70\% ice-ethanol, incubated 3 4 h at $4{ }^{\circ} \mathrm{C}$ and preserved in a refrigerator at $-20^{\circ} \mathrm{C}$ overnight. To remove the stationary liquid, the cells were centrifuged and washed twice with cold PBS. Then, $500 \mu \mathrm{L}$ mix dye solution (RNas eA $100 \mu \mathrm{g} / \mathrm{mL}$, PI $50 \mu \mathrm{g} / \mathrm{mL}$, Triton X -100 0.2\%) were added into each tube, gently mixed and incubated for $10 \mathrm{~min}$ at room temperature in the dark. Before analysis by using flow cytometry, the cells were washed with cold PBS, and $200 \mu$ l suspension were used analysis by a Novo Cyte flow cytometer (ACEA Biosciences, Inc., San Diego, CA, USA) using Novo Express 1.0.2 software. Each experiment was conducted three times.

\section{Real-Time PCR Assays}

Table 1: Nucleotide sequences of primers used for real-time RT-PCR.

\begin{tabular}{|c|c|c|}
\hline Genes & Forward Primer (5' $\mathbf{-} \mathbf{3}$ ) & Reverse Primer $\mathbf{( 5}$ ' $\mathbf{3}$ ') \\
\hline miR17 & TCTATTTCAAATTTAGCAGGAAAAA & AAGCACTCAACATCAGCAGG \\
\hline miR18a & GCAGTGAAGGCACTTGTAGC & TGCAAAACTAACAGAGGACTGC \\
\hline miR19a & CCTAAGTGCTCCTTCTGGCA & CCAGGCAGATTCTACATCGAC \\
\hline miR19b & TGTAGAACTCCAGCTTCGGC & ACACAGCATTGCAACCGAT \\
\hline miR20a & TGTCGATGTAGAATCTGCCTG & CAAACCTGCAAAACTAACCATAGA \\
\hline miR92 & TGGTAGTGAAAAGTCTGTAGAAAAGT & CATGTATCTTGTACATTTAACAGTGGA \\
\hline
\end{tabular}

GZWM-060 treated GZWM-060cells in different concentration $(0.15$ to $1 \mu \mathrm{mol} / \mathrm{L})$ for $16 \mathrm{~h}$, cells were collected. Total RNA was extracted by Trizol reagent according to the manufacturer's instructions (Invitrogen, Carlsbad, CA) and quantified using a Nanodrop ND-1000 spectrophotometer (Thermo Fisher Scientific, USA). Complementary DNA was synthesized in a $20 \mu$ reaction 
containing one $\mu \mathrm{g}$ of total RNA, using PrimeScript ${ }^{\mathrm{TM}}$ RT reagent Kit (Takara Bio Group) according to the manufacturer's instructions. To examine the quality, the cDNA was amplified by the beta-actin gene using the Taq Master Mix (Tiangen Beijing, China), and 1\% agarose gel electrophoresis was performed. Subsequently, to determine the mRNA levels of miR17, miR18a, miR19a, miR19b, miR 20a, miR 92, qRT-PCR was performed by using SYBR Green qPCR Master, the quantitative analysis of the change in expression levels was calculated by ABI 7300 real-time PCR machine (Applied Biosystems, Carlsbad, CA), the cycling condition was as follows, $95{ }^{\circ} \mathrm{C}$ for $15 \mathrm{~min}$ followed by 40 cycles of $95^{\circ} \mathrm{C}$ for $30 \mathrm{~s}$ and $60^{\circ} \mathrm{C}$ (primer TM) for $30 \mathrm{~s}, 72^{\circ} \mathrm{C}$ for $60 \mathrm{~s}$. All data were controlled for the quantity of RNA input by performing measurements on the endogenous reference gene $\beta$-actin. As well as, RNA results from treated samples were normalized to results obtained using RNA from the control. An average of three experiments each performed three times with standard errors is presented. Primer quality was analyzed by dissociation curves. Primer sequences are listed in Table 1. Data were analyzed by comparing Ct values.

\section{Western Blot Analysis}

Cells were treated by GZWM-060 in different concentration ( 0.15 to $1 \mu \mathrm{mol} / \mathrm{L}$ ) for $18 \mathrm{~h}$, cells were extracted and total protein was collected from cells in RIPA lysis buffer. Protein's concentration was determined by the level of protein BCA test kit (Solarbio life sciences, China), and proteins were separated by 10\% SDSPAGE, then blotted onto PVDF membrane $(0.22 \mu \mathrm{m}$, Merck KGaA, Germany). The membranes were incubated in solution with $3 \%$ BSA (dissolved in TBST) at room temperature for $1 \mathrm{~h}$ and probed with primary antibodies STAT3(1:1000), p-STAT3(1:1000), Bim (1:1000), and GAPDH $(1: 2000)$ at $4^{\circ} \mathrm{C}$ overnight. After washing with TBST 3 times, the membrane was incubated with secondary antibody. Finally, immunoreactive protein signals were detected using the Odyssey Infrared Imaging System. GAPDH was used as an internal loading control. Shown are representative data from individual experiments that were repeated at least twice.

\section{Statistical Analysis}

Experimental data were valued by a mean \pm standard deviation of three independent assays. All tests were carried out three times. An independent test was conducted for comparison between groups. Statistical significance was determined using Student's t-tests. Statistically different values were defined significant at $* \mathrm{P}<$ $.05, * * \mathrm{P}<.01$, and $* * * \mathrm{P}<.001$.

\section{Results}

\section{Cytotoxic Effects of The Compound GZWM-060 On HEL Cells}

Midostaurin (PKC412), a semi-synthetic derivative of staurosporine has a strong ability to kill leukemia cells in patients with positive oncogenic FLT3. To obtain more effective candidates' drugs for the treatment of leukemia patients. We synthesized many compounds from the skeleton of PKC412 and evaluated the cytotoxicity of these compounds on the human leukemia cell line (HEL) by using MTT assay. The observed results demonstrated that the GZWM-060 showed strong anti-cancer activity against HEL. (Table 2) The observed IC50 value of GZWM-060 against HEL was $0.3558 \pm 0.0673 \mu \mathrm{M}(72 \mathrm{~h})$, and the IC50 value of the positive drug PKC412 against HEL was $0.6638 \pm 0.3667 \mu \mathrm{M}(72 \mathrm{~h})$. To observe whether GZWM-060 could inhibit the growth of HEL cells in a dose- and time-dependent manner, the HEL cells were treated with different concentration of GZWM-060 (0.15, 0.3, 0.5, 1, $3 \mu \mathrm{mol} / \mathrm{L})$ and incubated for different time periods at $24,48,72 \mathrm{~h}$ in three independent assays to detect the cell viability. The results showed that the compound GZWM-060 could inhibit HEL growth in a doseand time-dependent manner. Interestingly, the compound exerted higher effective against HEL cells growth than PKC412 (Figure 1).

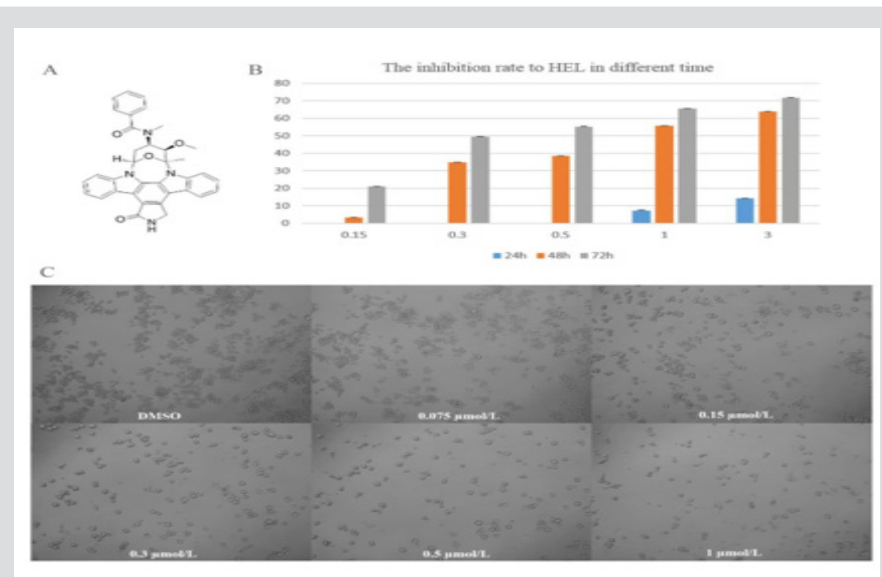

Figure 1: The inhibition rate to HEL cell.

A. The chemical structure of PKC412;

B. The dose-time- response curve of the HEL cell line derived from MTT cytotoxicity assay performed;

C. Morphological changes of the leukemia cell line of HEL treatment with different concentration of GZWM-060 in 72h. Data are presented as mean \pm standard error $(n=3)$. 
Table 2: The Inhibition rate of GZWM-060 to HEL cell.

\begin{tabular}{|c|c|c|c|}
\hline & & Inhibition Rate (\%) & \\
\hline Concentration $(\mu \mathrm{mol} / \mathrm{L})$ & $24 \mathrm{~h}$ & $48 \mathrm{~h}$ & $72 \mathrm{~h}$ \\
\hline 0.15 & 0 & $3.22 \pm 0.138$ & $21.08 \pm 0.080$ \\
\hline 0.3 & 0 & $34.95 \pm 0.027$ & $49.53 \pm 0.087$ \\
\hline 0.5 & 0 & $38.45 \pm 0.082$ & $55.20 \pm 0.103$ \\
\hline 1 & $7.25 \pm 0.144$ & $55.64 \pm 0.040$ & $65.63 \pm 0.033$ \\
\hline 3 & $14.24 \pm 0.028$ & $63.82 \pm 0.021$ & $71.70 \pm 0.029$ \\
\hline
\end{tabular}

response curve of the HEL cell line derived from MTT cytotoxicity

line of HEL treatment with different concentration of GZWM-060 in assay performed; C. Morphological changes of the leukemia cell 72h. (Table 3) Data are presented as mean \pm standard error $(n=3)$.

Table 3: The Inhibition rate of PKC412 to HEL cell (72h).

\begin{tabular}{|c|c|}
\hline Concentration $(\boldsymbol{\mu m o l} / \mathbf{L})$ & Inhibition Rate (\%) \\
\hline 0.3 & $21.59 \pm 0.210$ \\
\hline 0.5 & $59.46 \pm 0.042$ \\
\hline 1 & $62.55 \pm 0.050$ \\
\hline 3 & $73.93 \pm 0.038$ \\
\hline 5 & $76.60 \pm 0.027$ \\
\hline
\end{tabular}

\section{The Compound GZWM-060 Induced HEL Cells Apoptosis}

Apoptosis is central to block cancer cells growth. To study whether the compound GZWM-060 block HEL cells growth through inducing apoptosis, the effects of GZWM-060 on cell apoptosis were investigated by flow cytometry after staining with Annexin $\mathrm{V}$ and propidium iodide. The results showed that the treatment with GZWM- 060 for $24 \mathrm{~h}, 48 \mathrm{~h}, 72 \mathrm{~h}$ significantly induced apoptosis in HEL cells in a dose- and time-dependent manner (Figure 2).

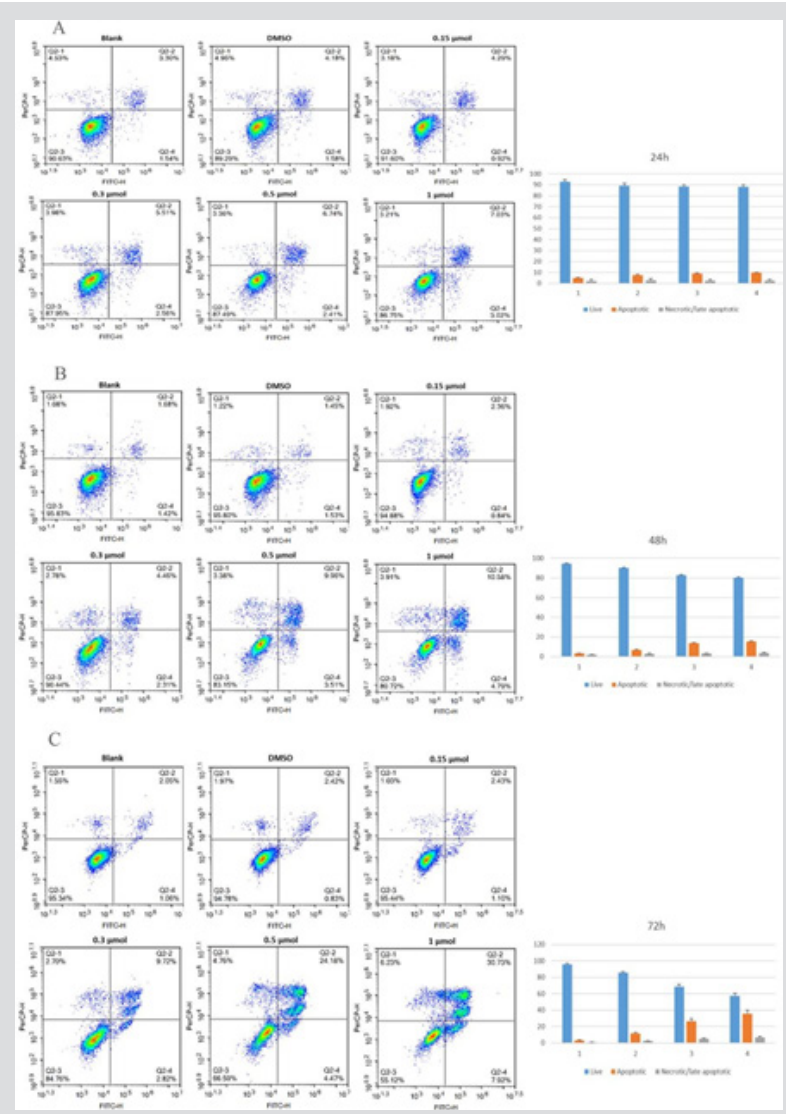

Figure 2: The apoptosis result of HEL cell in different time at different concentration of GZWM- 060 (0.15-1 $\mu \mathrm{mol} / \mathrm{L})$.
A. The apoptosis result of HEL cell in $24 \mathrm{~h}$
B. The apoptosis result of HEL cell in $48 \mathrm{~h}$
C. The apoptosis result of HEL cell in $72 \mathrm{~h}$ 
The Compound GZWM-060 Induced HEL Cells Differentiation into Erythrocytes the Induction of Terminal Differentiation in Cancer Cells Is A Central Way to Arrest

cancer cells growth. The human erythroleukemia cell line (HEL) is an established model to study erythroid and megakaryocytic differentiation in response to small molecular stimulation in vitro
[13]. To determine whether the compound GZWM-060 block cells growth through inducing differentiation in HEL cells. As a result, the flow cytometric analysis demonstrated that the expression of CD235a (an erythrocyte differentiation marker) of the HEL cell was increased after treatment with GZWM-060. Therefore, the data exposed that GZWM-060 might have a substantial effect on inducing HEL cells differentiation, and the up-regulation of differentiation marker present a dose-independent manner (Figure 3A).

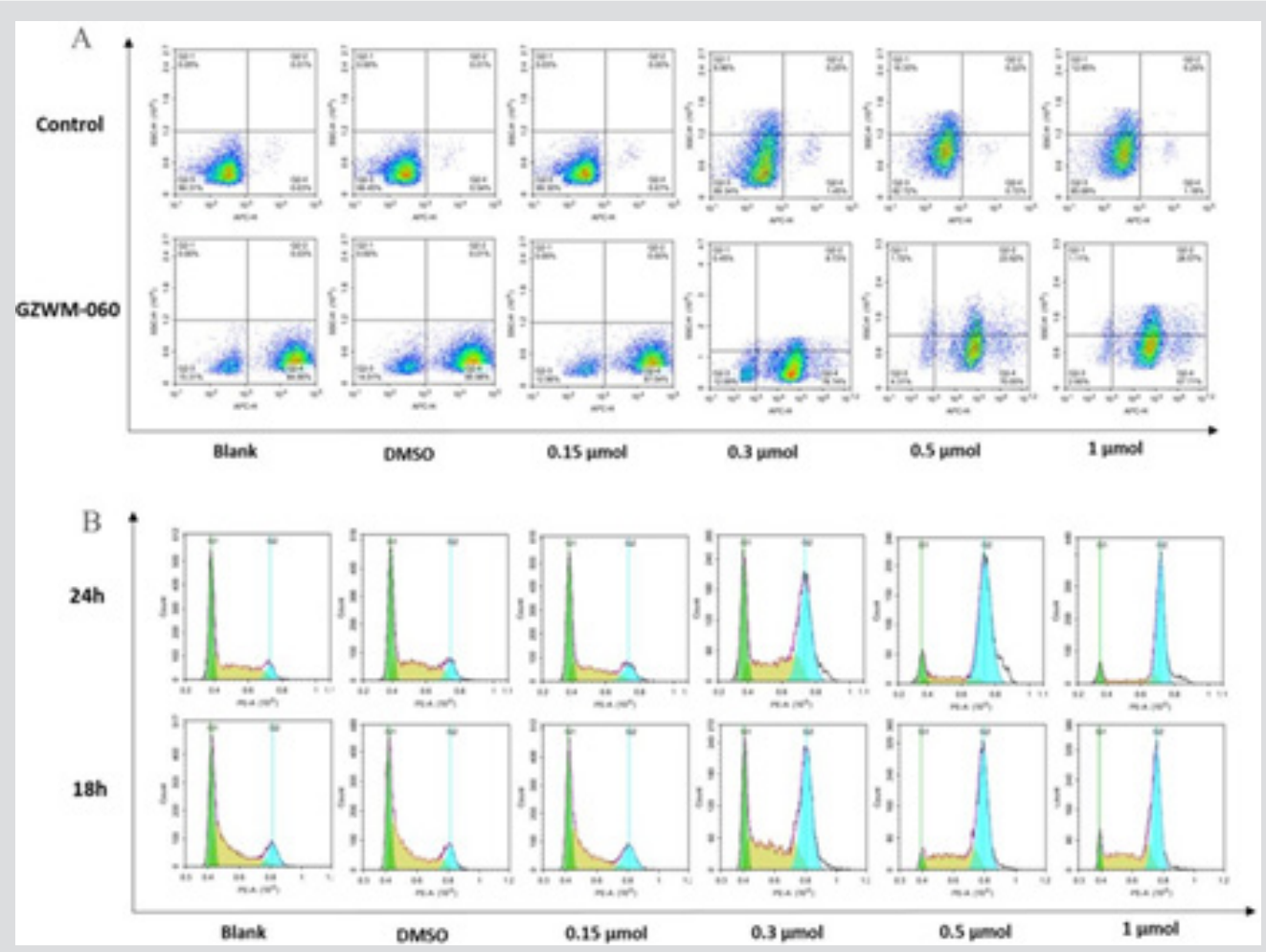

Figure 3: The results of flow cytometry.

A. The differentiation results of CD235a in HEL cell at different concentration of GZWM-060 $(0.15-1 \mu \mathrm{mol} / \mathrm{L}$.

B. The cell cycle result of HEL cell in different time $(18 \mathrm{~h}, 24 \mathrm{~h})$ at different concentration of GZWM-060 $(0.15-1 \mu \mathrm{mol} / \mathrm{L})$.

\section{The Compound GZWM-060 Arrested HEL Cell Cycle}

To identify whether the growth inhibitory effect of HEL cells caused by specific disruption of the cell cycle-related event, the cell cycle phase distributions was measured using a flow cytometric analysis. HEL cells were treated with GZWM-060 at different concentration for $18 \mathrm{~h}$ and $24 \mathrm{~h}$. The observations revealed the number of cells in the G1 phase significantly decreased in both cell lines, and the G2 phase significantly increased, which exerted a dose-independent manner (Figure 3B).

\section{The Compound GZWM-060 Inhibited the Expression of Mir-17-92}

MiR-17-92 plays a vital role in activating cancer cells proliferation [14]. To evaluate whether the compound GZWM-060 inhibit the expression of miR-17-92 in HEL cells, the expression of
miR-17-92 was analyzed in HEL cells treated with the compound GZWM-060 by using qRT-PCR. miR17, miR18a, miR19a, miR19b, miR20a, miR92 were significantly down-regulated after treated with GZWM-060 compared with DMSO control group (Figure 4A).

\section{The Effects of The Compound GZWM-060 on Proteins of Down or Up-Stream of Mir-17-92}

Our previous work indicated that STAT3 could enhance the expression of miR-17-92 by binding its promoter, and BIM is a target of miR-17-92 [15]. BIM and p-STAT3 are the critical regulators of apoptosis and cell cycle proteins. To validate the effects of GZWM060 on p-STAT3 and BIM protein levels in HEL cells, we examined protein levels of BIM and p-STAT3 by using western blot. The results showed that the protein level of BIM was up-regulated, but the p-STAT3 level was down-regulated in HEL cells treated with the compound GZWM-060 (Figure 4B). 


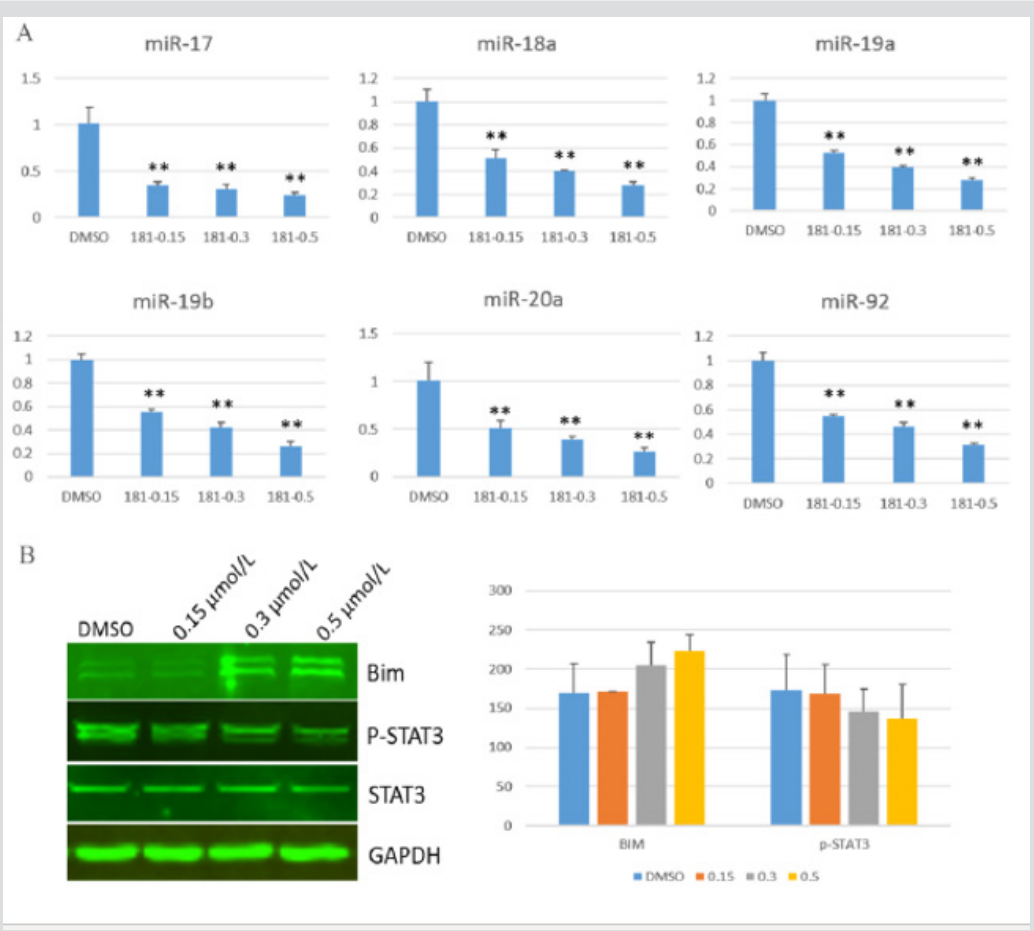

Figure 4: The result of Qrt-PCR and western blot.

A. The expression level of miR17-92 IN HEL cell with different concentration of GZWM-060 (0.15-0.5 $\mu \mathrm{mol} / \mathrm{L}$;

B. The expression level of protein with different concentration of GZWM-060 (0.15-0.5 $\mu \mathrm{mol} / \mathrm{L})$.

\section{Discussion}

To meet the continuous demand, a constant and sufficient supply of anticancer drugs is essential. Although many compounds possess anticancer effects, the underlying molecular mechanisms remain to be established. PKC 412 was first synthesized in 1986 [16] and was initially developed as a small molecular inhibitor of protein kinase C (PKC) [17]. Studies to investigate its potential as a PKC inhibitor revealed that it inhibited cell proliferation by interfering with cell-cycle activity $[18,19]$. Understanding the antitumor activity of mechanism can facilitate the foundation of a new target for treatment. In our study, we synthesized the compound GZWM-060 from the skeleton of PKC412 and found that GZWM060 could inhibit cells proliferation and exerts cytotoxicity against human leukemia HEL with an IC50 value of $0.3558 \pm 0.0673 \mu \mathrm{M}$. Further studies indicated that GZWM-060 induced apoptosis and arrested the cell cycle in leukemia cell, promoted the differentiation into erythrocytes. These results showed that GZWM-060 might be a lead molecule for the development of new anti-cancer drugs candidates.

Apoptosis is a highly synchronized and conserved cellular phenomenon maintained by a highly organized network of intrinsic cellular suicide machinery. When the homeostasis between cell proliferation and death is disturbed, apoptosis-inducing pathways are altered, which results in oncogenesis [20]. The induction of apoptosis in cancer had been identified as a target for the treatment of cancer $[21,22]$. There have two distinct signaling pathways of apoptosis, the intrinsic or mitochondrial pathway, and the extrinsic or death receptor pathway $[23,24]$. The regulation of these apoptotic mitochondrial events occurs through members of the Bcl-2 family of the protein [25] and is classified into one anti-apoptotic and two pro-apoptotic groups, which BIM belong to the pro-apoptotic proteins [23]. The western blot results show that the molecular mechanism of apoptosis induction by GZWM-060 includes modulation of the protein expression of BIM. BIM-induced apoptosis is critical for the development and homeostasis of immune cells [26]. In the past decade, BIM has been recognized as an essential pro-apoptotic protein for initiating the intrinsic apoptotic pathway under many physiological and pathophysiological conditions [27], De Bruyne discovered that BIM promoter acetylation was linked to increased BIM expression in multiple myeloma and aggravated apoptosis [28].

The western blot experiments revealed that p-STAT3 was inhibited by GZWM-060, with exposure to GZWM-060 at 0.15, 0.3 and $0.5 \mu \mathrm{M}$, the level of phosphorylated STAT3 (p -STAT3) was decreased compared to the untreated group. The reduced expression of p-STAT3, as well as increased cell apoptosis, presented themselves in a time and concentration-dependent manner. Progression by the cell cycle phases (G1, S, G2, M) is under the control of a family of serine/threonine protein kinases [29]. BIM plays a vital role in the regulation of cell cycle. Activating BIM lead to cells growth inhibition at specific stages in the cell cycle [15]. The anti-proliferative activity of GZWM-060 also involves an increase in BIM protein level, which disruption of cell cycle process plays a role in the anti-oncogenic. BIM also binds to and represses the transcription factor signal transducer and activator of transcription 3 (STAT3), thereby inhibiting cytokine-stimulated and STAT3dependent gene expression [30], that consistent with our results. The family of STAT protein includes seven transcription factors: STAT1, STAT2, STAT3, STAT4, STAT5a, STAT5b and STAT6 [31]. 
STAT3 has been noticed as one of the critical factors for tumors formation [32] and has a crucial role in breast cancer initiation [33]. In natural cells, STAT3 activation is tightly controlled, but activated STAT3 (p-STAT3) has been identified in many kinds of human tumor samples and cancer cell lines, which indicates it plays a pivotal role in the process of tumor development [34]. Recent studies have demonstrated that p-STAT3 overexpression is associated with poorer prognosis in patients with some cancer [35-37], and some studies indicated that p-STAT3 enters into the nucleus and promotes cell proliferation, drug resistance and suppresses tumor cell apoptosis [38,39]. MicroRNAs are types of small non-coding RNAs whose mature products are $\sim 22$

nucleotides long, which get involved in various biological processes including the cell cycle, differentiation, growth, and development, metabolism, aging and apoptosis [40,41]. In 2005, He et al. first discovered the miR-17-92 cluster, an oncogenic gene in human B-cell lymphomas [42]. The miR-17-92 cluster is a typical highly conserved polycistronic miRNA cluster, which is located in the human chromosome 13, encoding six mature miRNAs, including miR-17, miR-18a, miR-19a, miR-19b, miR-20a and miR-92a [43].

MiR-17-92 play an essential role in both the apoptotic and cellproliferation pathways $[44,45]$. Jack's lab showed that deletion of miR-17-92 could induce up-regulation of the pro-apoptotic protein BIM by using miR-17-92 knockout mice [46]. Li et al. discovered that miR-17-92 could activate BIM when they knocked down miR92, cell cycling was arrested at G1/S via up-regulation of BIM [15] Besides, it has been demonstrated that the miR-17-92 cluster can inhibit the expression of the tumor suppressor and the apoptotic gene BIM in lymphoma [47]. In our study, the result of qRT-PCR indicated that the expression of miR17-92 down-regulation by GZWM- 060 and western blot showed that both of the expression of BIM was increased, so GZWM-060 maybe as a drug candidate by targeting to the STAT3/miR-17-92/BIM signal pathway.

\section{Acknowledgements}

This work was supported by grants from the National Natural Science Foundation of China (81700169, 81502959, 21502034, 30572246 and 30973680), the Natural Science Foundation of Guizhou (QKH 20181409), the 100 Leading Talents of Guizhou Province (fund for Y. Li and W. Zhu), QKHPTRC2017 (5737), Light of the Western Talent Cultivation Program of the Chinese Academy of Sciences (201684).

\section{Disclosure Statement}

The authors declared no conflicts of interest. W. Zhu designed and L. Wang synthesized the compound, GZWM-060.

\section{References}

1. Ferlay J, Soerjomataram I, Dikshit R, Eser S, Mathers C, et al. (2015) Cancer incidence and mortality worldwide: sources, methods and major patterns in Globocan 2012. International journal of cancer 136(5): E359-386.

2. Ling Yang Dmp, Parkin DM, Jacques Ferlay, Liandi Li, Yude Chen, et al. (2005) Estimates of Cancer Incidence in China for 2000 and Projections for 2005. Cancer Epidemiol Biomarkers Prev 14(1): 243-50.
3. Bray F, Moller B (2006) Predicting the future burden of cancer. Nature reviews Cancer 6(1):63-74.

4. Jemal A, Bray F, Center MM, Ferlay J, Ward E, et al. (2011) Global cancer statistics. CA: a cancer journal for clinicians 61(2): 69-90.

5. Kossai M, Duchemann B, Boutros C, Caramella C, Hollebecque A, et al (2015) Antitumor activity in advanced cancer patients with thymic malignancies enrolled in early clinical drug development programs (Phase I trials) at Gustave Roussy. Lung cancer 89(3): 306-310.

6. Welch JS, Ley TJ, Link DC, Miller CA, Larson DE, et al. (2012) The origin and evolution of mutations in acute myeloid leukemia. Cell 150(2): 264278.

7. Khwaja A, Bjorkholm M, Gale RE, Levine RL, Jordan CT, et al. (2016) Acute myeloid leukaemia. Nature reviews Disease primers 2: 16010.

8. Molly M, Gallogly HM, LaBWC (2017) Midostaurin: a novel therapeutic agent for patients with FLT3-mutated acute myeloid leukemia and systemic mastocytosis. Therapeutic Advances in Hematology 8(9): 245261.

9. Fabbro DBE, Wood J, Mestan J, Hofmann F, Ferrari S, et al. (1999) Inhibitors of protein kinases: CGP 41251, a protein kinase inhibitor with potential as an anticancer agent. Pharmacol Ther 82(2-3): 293-301.

10. Florian Heidel FKS, Frank Breitenbuecher, Daniel B Lipka, Stefan Kasper, M H Thiede, et al. (2006). Clinical resistance to the kinase inhibitor PKC412 in acute myeloid leukemia by mutation of Asn-676 in the FLT3 tyrosine kinase domain. Blood 107(1): 293-300.

11. Williams ABNB, Li L, Brown P, Levis M, Leahy D, et al. (2013) Mutations of FLT3/ITD confer resistance to multiple tyrosine kinase inhibitors. Leukemia 27(1): 48-55.

12. Jan Cools NM, Pascal Furet, Doriano Fabbro, Jennifer JClark, James D Griffin, et al. (2004) Prediction of Resistance to Small Molecule FLT3 Inhibitors: Implications for Molecularly Targeted Therapy of Acute Leukemia. Cancer Research 64(18): 6385-6389.

13. Fuchs R, Stelzer I, Haas HS, Leitinger G, Schauenstein K, et al. (2009) The alpha1- adrenergic receptor antagonists, benoxathian and prazosin, induce apoptosis and a switch towards megakaryocytic differentiation in human erythroleukemia cells. Annals of hematology 88(10): 989-997.

14. Li Y, Vecchiarelli-Federico LM, Li YJ, Egan SE, Spaner D, et al. (2012) The miR-17-92 cluster expands multipotent hematopoietic progenitors whereas imbalanced expression of its individual oncogenic miRNAs promotes leukemia in mice. Blood 119(19): 4486-4498.

15. Xu Z, Sharp PP, Yao Y, Segal D, Ang CH, et al. (2016) BET inhibition represses miR17-92 to drive BIM-initiated apoptosis of normal and transformed hematopoietic cells. Leukemia 30: 1531-1541.

16. Caravatti G MT, Fredenhagen A, Trinks U, Mett H, Fabbro D, et al. (1994) Inhibitory activity and selectivity of staurosporine derivatives towards protein kinase C. Bioorg Med Chem Lett 4(3): 399-404.

17. Meyer T RU, Fabbro D, Alteri E, Rosel J, Muller M, et al. (1989) A derivative of staurosporine (CGP 41251 ) shows selectivity for protein kinase $\mathrm{C}$ inhibition and in vitro anti-proliferative as well as in vivo antitumor activity. Int J Cancer 43(5): 851-856.

18. Yuri Ikegami SY, Kenzo Nakao (1996) Antitumor Effect of CGP41251, a New Selective Protein Kinase C Inhibitor, on Human Non-Small Cell Lung Cancer Cells. Jpn J Pharmacol 70(1): 65-72.

19. Ikegami Y YS, Nakao K (1996) Effects of the new selective protein kinase C inhibitor 4'- N-benzoyl staurosporine on cell cycle distribution and growth inhibition in human small cell lung cancer cells. Arzneimittelforschung 46(2): 201-204.

20. Douglas Hanahan, Weinberg RA (2000) The Hallmarks of Cancer. Cell 100(1): 57-70.

21. Fisher DE (1994) Apoptosis in Cancer Therapy: Crossing the Threshold. Cell 78(4): 539-42. 
22. Attardi JMBaLD (2005) The role of apoptosis in cancer development and treatment response. Nature reviews Cancer 5(3): 231-237.

23. Elmore S (2007) Apoptosis: A Review of Programmed Cell Death. Toxicol Pathol 35(4): 495-516.

24. Kapoor R, Rizvi F, Kakkar P (2013) Naringenin prevents high glucoseinduced mitochondria-mediated apoptosis involving AIF Endo-G and caspases. Apoptosis: an international journal on programmed cell death 18(1): 9-27.

25. Cory S, Adams JM (2002) The Bcl2 family: regulators of the cellular lifeor-death switch. Nature reviews Cancer 2(9): 647-656.

26. Bouillet P, Metcalf D, Huang DC, Tarlinton DM, Kay TW, et al. (1999) Proapoptotic Bcl-2 Relative Bim Required for Certain Apoptotic Responses, Leukocyte Homeostasis, and to Preclude Autoimmunity. Science (New York, NY) 286(5445): 1735-1738.

27. Shukla S, Saxena S, Singh BK, Kakkar P (2017) BH3-only protein BIM: An emerging target in chemotherapy. European journal of cell biology 96(8): 728-738.

28. De Bruyne E, Bos TJ, Schuit F, Van Valckenborgh E, Menu E, et al. (2010) IGF-1 suppresses Bim expression in multiple myeloma via epigenetic and posttranslational mechanisms. Blood 115(12): 2430-2440.

29. Malumbres M, Barbacid M (2005) Mammalian cyclin-dependent kinases. Trends in biochemical sciences 30(11): 630-641.

30. Coqueret O, Gascan H (2000) Functional interaction of STAT3 transcription factor with the cell cycle inhibitor p21WAF1/CIP1/SDI1. The Journal of biological chemistry 275(25): 18794-18800.

31. Darnell Jr JE (1997) STATs and Gene Regulation. Science (New York, NY) 277(5332): 1630-1635.

32. Tammy Bowman RG, James Turkson, Richard Jove (2000) STATs in oncogenesis. Oncogene.19(21): 2474-2488.

33. Chang Q, Bournazou E, Sansone P, Berishaj M, Gao SP, et al. (2013) The IL6/JAK/Stat3 Feed-Forward Loop Drives Tumorigenesis and Metastasis. Neoplasia 15(7): 848-IN45.

34. Munoz J, Dhillon N, Janku F, Watowich SS, Hong DS, et al. (2014) STAT3 inhibitors: finding a home in lymphoma and leukemia. The oncologist 19(5): 536-544.

35. Yuichi Yakata TN, Ayumi Yoshizaki, Takafumi Kusaba, Kenichiro Inoue, Ichiro Sekine, et al. (2007) Expression of p-STAT3 in human gastric carcinoma: Significant correlation in tumour invasion and prognosis. International Journal of Oncology 30(2): 437-442.

\section{ISSN: 2574-1241}

DOI: 10.26717/BJSTR.2019.17.002944

Yanmei Li. Biomed J Sci \& Tech Res

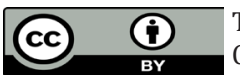

This work is licensed under Creative Commons Attribution 4.0 License

Submission Link: https://biomedres.us/submit-manuscript.php
36. Wormann SM, Song L, Ai J, Diakopoulos KN, Kurkowski MU, et al. (2016) Loss of P53 Function Activates JAK2-STAT3 Signaling to Promote Pancreatic Tumor Growth, Stroma Modification, and Gemcitabine Resistance in Mice and Is Associated with Patient Survival. Gastroenterology 151(1): 180-193 e12.

37. Xu YH, Lu S (2014) A meta-analysis of STAT3 and phospho-STAT3 expression and survival of patients with non-small-cell lung cancer. European journal of surgical oncology: the journal of the European Society of Surgical Oncology and the British Association of Surgical Oncology 40: 311-317.

38. Vogelstein B, Kinzler KW (2004) Cancer genes and the pathways they control. Nature medicine 10(8): 789-799.

39. Teng Y, Ross JL, Cowell JK (2014) The involvement of JAK-STAT3 in cell motility invasion and metastasis. Jak-Stat 3(1): e28086.

40. Hu G, Drescher KM, Chen XM (2012) Exosomal miRNAs: Biological Properties and Therapeutic Potential. Frontiers in genetics 3: 56.

41. Rottiers V, Naar AM (2012) MicroRNAs in metabolism and metabolic disorders. Nature reviews Molecular cell biology 13(4): 239-250.

42. He L, Thomson JM, Hemann MT, Hernando-Monge E, Mu D, et al. (2005) A microRNA polycistron as a potential human oncogene. Nature 435(7043): 828-833.

43. Akinobu Ota HT, Sivasundaram Karnan, Shinobu Tsuzuki, Abraham Karpas, Shigeki Kira, et al. (2004) Identification and Characterization of a Novel Gene, C13orf25, as a Target for 13q31-q32 Amplification in Malignant Lymphoma. Cancer Research 64(9): 3087-3095.

44. Adhikary S, Eilers M (2005) Transcriptional regulation and transformation by Myc proteins. Nature reviews Molecular cell biology 6(8): 635-645.

45. Julie Secombe SBP, Robert N Eisenman (2004) Myc: A Weapon of Mass Destruction. Cell 117(2): 153-156.

46. Andrea Ventura AGY, Monte M Winslow, Laura Lintault, Alex Meissner, StefanJ Erkeland, et al. (2008) Targeted deletion reveals essential and overlapping functions of the miR-17 92 family of miRNA clusters. Cell 132(5): 875-886

47. Letizia Venturini KB, Mirco Castoldi, Beate Schultheis, Andreas Hochhaus, Martina U Muckenthaler, et al. (2007) Expression of the miR17-92 polycistron in chronic myeloid leukemia (CML) CD34 cells. Blood 109(10): 4399-4405.

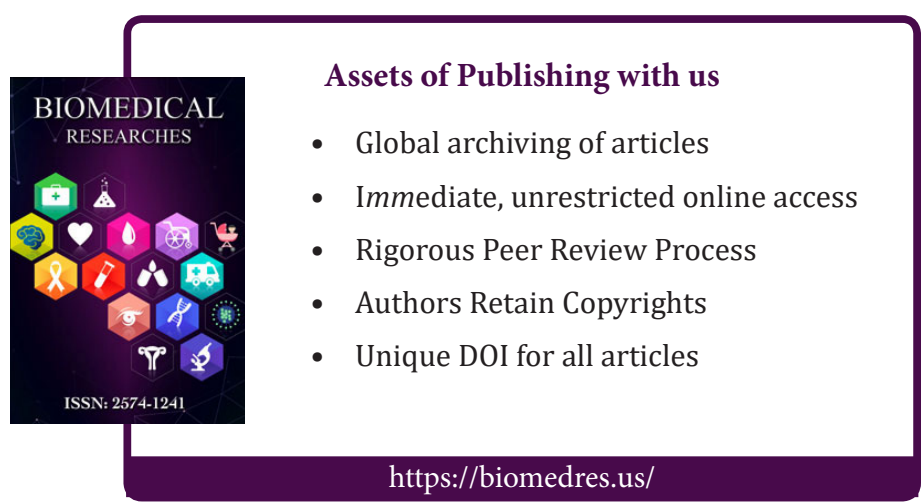

